Document downloaded from:

http://hdl.handle.net/10251/47136

This paper must be cited as:

Moreno Chou, AT.; Llorca Garcia, C.; García García, A.; Pérez Zuriaga, AM. (2013).

Operational effectiveness of passing zones depending on their length and traffic volume.

Transportation Research Record. (2395):57-65. doi:10.3141/2395-07.

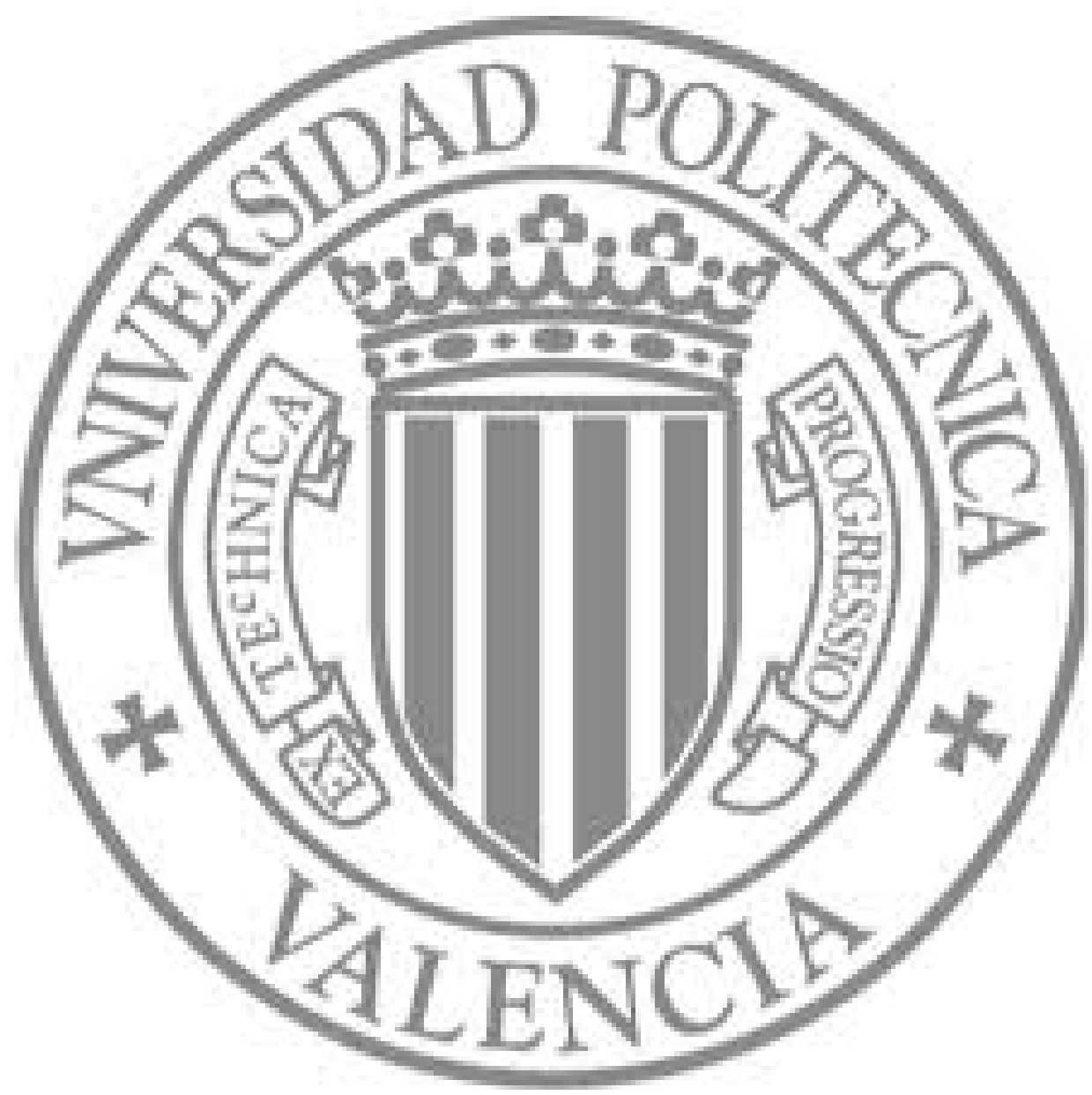

The final publication is available at

http://dx.doi.org/10.3141/2395-07

Copyright National Academy of Sciences 


\title{
OPERATIONAL EFFECTIVENESS OF PASSING ZONES DEPENDING ON THEIR LENGTH AND TRAFFIC VOLUME \\ Corresponding Author:
}

\author{
Ana Tsui Moreno \\ Ph.D. Candidate
}

Highway Engineering Research Group

Universitat Politècnica de València

Camino de Vera, s/n. 46022 - Valencia. Spain

Tel: (34) 963877374

Fax: (34) 963877379

E-mail: anmoch@cam.upv.es

Other Authors:

\section{Carlos Llorca}

Ph.D. Candidate

Highway Engineering Research Group, Universitat Politècnica de València Camino de Vera, s/n. 46022 - Valencia. Spain

Tel: (34) 963877374

Fax: (34) 963877379

E-mail: carlloga@cam.upv.es

\section{Alfredo García}

Professor

Highway Engineering Research Group, Universitat Politècnica de València Camino de Vera, s/n. 46022 - Valencia. Spain

Tel: (34) 963877374

Fax: (34) 963877379

E-mail: agarciag@tra.upv.es

\section{Ana María Pérez-Zuriaga}

Ph.D.

Highway Engineering Research Group, Universitat Politècnica de València Camino de Vera, s/n. 46022 - Valencia. Spain

Tel: (34) 963877374

Fax: (34) 963877379

E-mail: anpezu@tra.upv.es

Submission date: July $27^{\text {th }}, 2012$

Word count: Abstract: $\quad 315$

Manuscript: $\quad 5733$

Figures: 4 × $250=1000$

Tables: 6 × $250=1500$

Total: $\quad \mathbf{8 2 3 3}$

Key words: Traffic operation, passing zone, two-lane highway, time spent following. 


\section{ABSTRACT}

2 Two-lane highways operation has been deeply studied. Most of the studies are focused on percentage 3 of following vehicles or the adjustment of the HCM procedure to local data. The HCM proposes the 4 length of no-passing zones as a parameter on the model; however, the distribution and characteristics 5 of the passing zones along the highway are not addressed. In fact, only a few studies on the expected 6 number of passes on a passing zone have been carried out.

This research presents an analysis of the effectiveness of passing zones considering their length and traffic volume. Data were collected on four passing zones of one rural highway in Spain, with two-way traffic volumes ranging from $100 \mathrm{vh} / \mathrm{h}$ to $900 \mathrm{vh} / \mathrm{h}$ and lengths between 265 and 1270 $\mathrm{m}$. So, the influence of traffic flow on passing rates was calculated on the same passing zones. More than 1,600 passing maneuvers were recorded during the 53 hours of observation on the scenarios.

Operational effectiveness of passing zones was obtained from passing frequency, as the number of passes per time, and from passing rate, as the number of passes per time and following vehicle. It was found that the longer the passing zone, the higher passing frequency. However, the effectiveness of passing zones was stabilized from $1,100 \mathrm{~m}$. On the other hand, balanced flows with two-way traffic volumes between 600 and $700 \mathrm{veh} / \mathrm{h}$ optimized the number of passes. Nevertheless, passing rate decreased as traffic volume increased. So, the increase in the passing frequency with the traffic volume is lower than the increase of following vehicles.

The results were validated with additional 46-hour data from another twelve passing zones with different lengths and traffic volumes.

Finally, Highway Capacity Manual adjustments on average travel speed and percentage time spent following based on percentage of no-passing zones do not reliably represent effectiveness of passing zones. Effectiveness of every passing zone should be considered instead. 


\section{INTRODUCTION}

Two-lane highways have a level of interaction between vehicles traveling in the same and in opposing direction that results in unique operational characteristics; mainly because faster vehicles that want to travel at their desired speed face the on-coming traffic in the opposite lane and they may suffer delays because of their inability to pass slow-moving vehicles. Thus, passing maneuvers are used by drivers to relieve drivers stress, increase perceived level of service and reduce delay (1). On the other hand, passes are conditioned by the opposing lane occupation which generates a conflict area. In fact, even though passing is not one of the main causes of crashes in two-lane highways, its consequences are severe (2).

From a traffic operation perspective, the limited passing opportunities result in higher impact of slow-moving vehicles on traffic performance. The Highway Capacity Manual (HCM) utilizes the percentage time spent following (PTSF) and the average travel speed (ATS) as major performance indicators in two-lane highways (3). The effect of passes is reflected on the analysis procedure on both PTSF, depending on the combined effect of directional distribution of traffic and of the percentage of no-passing zones, and ATS, based on the percentage of no-passing zones.

In practice, PTSF is used as the indicator of platooning on two-lane highways; and refers to the percentage of travel time a vehicle is trapped in a platoon being unable to pass slow-moving vehicles. Many studies have been focused on PTSF and platooning (4 - 9), and they even developed new methodologies for estimating performance on two-lane highways based on the average number of headways inside and between platoons $(10)$ and using speed and headways $(5,11)$. The 3 -second headway rule was used to estimate the percentage following in most operational studies $(4,5,6,8,12$, 13), as set on the HCM (3). However, other authors proposed 4 or 5 seconds $(7,10,14,15,16)$. In fact, it was confirmed that interaction between successive vehicles on the same lane generally diminishes beyond a time headway threshold of 5-7 seconds (6). Besides, number of vehicles in platoons increase as traffic volume increases (10). Consequently, there is not a uniform criterion on the literature on following vehicles. PTSF is adjusted by the combined effect of the directional distribution of traffic and of the percentage of no-passing zones (3): the PTSF increases as the percentage of no-passing zones increases, for the same directional split; and it is maximum for a twoway flow rate equal to $400 \mathrm{pc} / \mathrm{h}$. As the traffic proportion is more favorable, its influence decreases.

On the other hand, larger percentage of no-passing zones decrease ATS (3), and it also depends on the demand flow rate. The effect of no-passing zones on ATS on two-way segments is maximum for two-way flow rate of $400 \mathrm{pc} / \mathrm{h}$. However, Luttinen (17) pointed out that the adjustments were obtained from simulations and no indications about the precision of the adjustment are given.

Morral and Werner (18) introduced the overtaking ratio for consideration as a measure of service on two-lane highways. The overtaking ratio was defined as the achieved passes divided by desired passes. The demand for passing was a function of the characteristics of drivers and vehicles while the supply of passing depended on the percentage of no-passing zones and the distribution of gaps in the opposing traffic stream. They stated that drivers' perception of level of service was based on their ability or inability to pass slower vehicles; and that ability depended on the supply of sufficient gaps in the opposing stream and sufficient sight distance; so, the overtaking ratio would better represent drivers' perception. Their findings supported the HCM and passing lanes could also be evaluated. However, the conclusions were based on simulations.

Moreover, the characteristics of the passing zone itself may influence on its effectiveness to allow passing maneuvers. From one of the only field studies on passing activities (1), it can be concluded that the longer the passing zone, the higher passes per unit length (passes $/ \mathrm{h} / \mathrm{km}$ ). Furthermore, passing maneuvers are limited and typically performed using the opposing lane when sight distance and gaps in the opposing traffic stream permit. Therefore, passing frequencies may be 
optimized on the same passing zone at some traffic volume, from which it will decrease the number of gaps in the opposing traffic stream and so the passing opportunities. Romana (1) found that passing was effective as relief and improvement of level of service for balanced flows around 500 to 800 $v e h / h$. However, the data sets were obtained from three highways with different lengths and traffic flows.

The present research deepens on the analysis of passing zones effectiveness considering the number of passes and the number of passes per following vehicle, depending on the passing zone length and traffic volume.

\section{OBJECTIVES AND HYPOTHESES}

The aim of this research is to analyze the operational effectiveness of passing zones depending on the passing zone length and the traffic volume. Data were collected on four passing zones of one rural highway in Spain, with two-way traffic volumes ranging from $100 \mathrm{vh} / \mathrm{h}$ to $900 \mathrm{vh} / \mathrm{h}$ and lengths between 265 and $1270 \mathrm{~m}$. So, the influence of traffic flow on passing rates was calculated on the same passing zones with different lengths. The effectiveness of passing zones was obtained from passing frequency, as the number of passing maneuvers (passes) per 15-minute period, and from passing rate, as the number of passing maneuvers per 15-minute period and following vehicle. The results were validated with additional data from another twelve passing zones with different lengths and traffic volumes.

Based on the literature, the following hypotheses have been established:

- Passing frequency and passing rate would increase as the length of the passing zone increases.

- Passing frequency and passing rate would increase as the two-way traffic flow increases until a maximum value, from which they would decrease as the gap sizes on the opposing traffic stream decrease.

\section{METHODOLOGY}

The methodology was conducted on three stages: field study; data reduction; and analysis of the results.

\section{Field study}

Data were collected in four passing zones on the N-225 highway in the province of Valencia, Spain. The total length of the highway segment is $15 \mathrm{~km}$ and it connects two major intercity routes and serves to daily commuter routes. Therefore, it can be classified as Class I two-lane highway. Design speed, as well as posted speed limit, is $100 \mathrm{~km} / \mathrm{h}$. Cross section was $3.5 \mathrm{~m}$ lane width and $1.5 \mathrm{~m}$ shoulder width. Annual average daily traffic was 5,577 veh/day in 2010.

The four passing zones, two on each travel direction, were located between stations $4+000$ and $6+000$ in a tangent; with a no-passing zone between them caused by a vertical crest curve (Figure 1). Their lengths were 265 and 1,270 $\mathrm{m}$ on the East bound; and 1,050 and $507 \mathrm{~m}$ on the West bound (Table 1).

A mobile traffic laboratory (19) was placed between the four passing zones next to the highway. It was equipped with six digital video cameras installed on the top of an elevator platform. Zoom and camera focus were adjusted on site using their wireless network to collect video images of the four passing zones simultaneously. Uniform quality on each zone was obtained. Videos were recorded a working day between $2 \mathrm{pm}$ and $9 \mathrm{pm}$. Two-ways traffic volumes ranged from 120 to 390 
$\mathrm{vh} / \mathrm{h}$. So, different traffic flows and traffic proportion could be analyzed on the same scenarios.

However, high-traffic volumes were not captured. Consequently, two additional data collection were carried out during two hours one Friday afternoon, with traffic volumes between 360 and $560 \mathrm{vh} / \mathrm{h}$; and another two hours one Sunday afternoon with traffic volumes between 560 and $900 \mathrm{vh} / \mathrm{h}$. The additional data were collected using two coordinated video cameras. One was located at the beginning of the longest passing zones and the other camera recorded the whole shortest passing zones. They were not perceived by drivers (Figure 1).
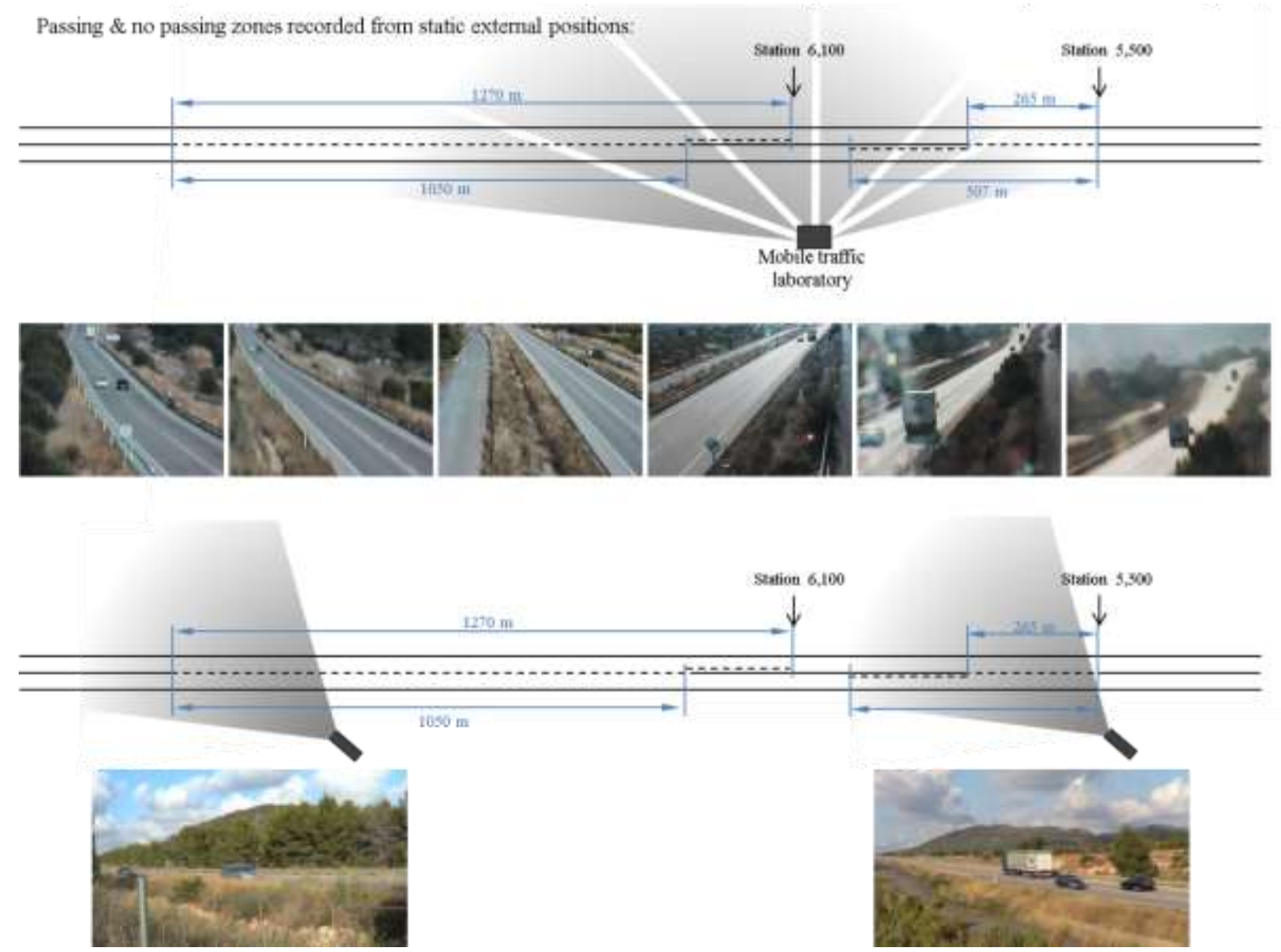

FIGURE 1 Field study design.

TABLE 1 Calibration passing zones characteristics

\begin{tabular}{|c|c|c|c|c|c|c|c|}
\hline ID & Highway & $\begin{array}{c}\text { Station } \\
\text { (m) }\end{array}$ & Bound & $\begin{array}{l}\text { Passing zone } \\
\text { length }(\mathbf{m})\end{array}$ & $\begin{array}{l}\text { Two-way traffic } \\
\text { volume (veh/h) }\end{array}$ & $\begin{array}{l}\text { Number } \\
\text { of passes }\end{array}$ & $\begin{array}{l}\text { Duration } \\
\text { (h) }\end{array}$ \\
\hline 1 & \multirow{4}{*}{ N-225 } & \multirow{2}{*}{5,500} & 1 & 265 & \multirow{4}{*}{$120-900$} & 148 & \multirow{4}{*}{ 13:00 } \\
\hline 2 & & & 2 & 507 & & 279 & \\
\hline 3 & & \multirow{2}{*}{6,100} & 1 & 1270 & & 680 & \\
\hline 4 & & & 2 & 1050 & & 542 & \\
\hline \multicolumn{6}{|c|}{ TOTAL } & 1,649 & 52:00 \\
\hline
\end{tabular}

In order to validate the conclusions from one highway segment, twelve more passing zones were analyzed. The mobile traffic laboratory was also parked next to the passing zone. Length and traffic flows of the passing zones, as well as video duration and number of passes, are summarized in Table 2. 
TABLE 2 Validation passing zones characteristics

\begin{tabular}{|c|c|c|c|c|c|c|c|}
\hline ID & Highway & $\begin{array}{c}\text { Station } \\
(\mathrm{m})\end{array}$ & Bound & $\begin{array}{c}\text { Passing zone } \\
\text { length }(\mathbf{m})\end{array}$ & $\begin{array}{l}\text { Two-way traffic } \\
\text { volume (veh/h) }\end{array}$ & $\begin{array}{l}\text { Number } \\
\text { of passes }\end{array}$ & $\begin{array}{c}\text { Duration } \\
\text { (h) }\end{array}$ \\
\hline 1 & \multirow{4}{*}{ CV-50 } & \multirow{2}{*}{84,500} & 1 & 600 & \multirow{2}{*}{$215-365$} & 52 & \multirow{2}{*}{ 4:00 } \\
\hline 2 & & & 2 & 850 & & 43 & \\
\hline 3 & & \multirow{2}{*}{77,500} & 1 & 990 & \multirow{2}{*}{$175-420$} & 15 & \multirow{2}{*}{$2: 50$} \\
\hline 4 & & & 2 & 755 & & 10 & \\
\hline 5 & \multirow{2}{*}{ CV-37 } & \multirow{2}{*}{14,000} & 1 & 550 & \multirow{2}{*}{$180-375$} & 25 & \multirow{2}{*}{ 3:00 } \\
\hline 6 & & & 2 & 560 & & 31 & \\
\hline 7 & \multirow{4}{*}{ CV-35 } & \multirow{2}{*}{76,000} & 1 & 540 & \multirow{2}{*}{$100-150$} & 5 & \multirow{2}{*}{$5: 55$} \\
\hline 8 & & & 2 & 522 & & 11 & \\
\hline 9 & & \multirow{2}{*}{44,500} & 1 & 1130 & \multirow{2}{*}{$180-305$} & 58 & \multirow{2}{*}{ 4:05 } \\
\hline 10 & & & 2 & 1265 & & 48 & \\
\hline 11 & \multirow{2}{*}{ CV-25 } & \multirow{2}{*}{5,000} & 1 & 1000 & \multirow{2}{*}{$310-1,100$} & 17 & \multirow{2}{*}{$3: 20$} \\
\hline 12 & & & 2 & 1000 & & 62 & \\
\hline \multicolumn{6}{|c|}{ TOTAL } & 377 & 46:20 \\
\hline
\end{tabular}

Data were collected with dry pavement conditions and good weather, during working days. The mobile traffic laboratory was proven not to influence passing maneuvers (19).

\section{Data reduction}

Video data was used to characterize passing frequency and passing rate. Traffic volumes, as well as following vehicles (FV) were also obtained. Moreover, accepted and rejected gaps, passing times and time-to-collision (TTC) were calculated for each passing maneuver for another research.

The counting period was 5 minutes and the results were aggregated in 15 minutes as the sum of three overlapping consecutive 5-minute period in order to skip the error of peak 15-minute period overlapped on two 15-minute counting periods (17).Then, equivalent hourly data were calculated based on the 15-minute data. Consequently, 45615 -minute periods were considered on the N-225, 114 15-minute periods per passing zone. A total of 553 15-minute periods were analyzed considering the additional passing zones. The 15-minute period was chosen over hourly period times in order to better represent passing maneuvers, as peak traffic volumes and traffic proportion are smoothed on hourly periods. Besides, the capacities and service flow rates of the HCM are based on 15-minute periods.

Three-second headway was used to determine following vehicles: all the vehicles that had headway lower than 3 seconds with the preceding car were considered following vehicles. Percentage of following vehicles on the 15 -minute period was calculated as the number of following vehicles divided by the number of vehicles on that traffic direction.

Passing maneuvers were obtained from the videos. As complete passing zones were recorded with the mobile traffic laboratory, passes were counted viewing the video. The shortest zones on the high-volume data collection were also recorded completely, so passing maneuvers were counted from the video without further data reduction. Passing maneuvers on the longest passing zones on highvolume data collection were obtained comparing the order of the vehicles at the beginning and the end of the passing zone. Whenever a change in sequence of vehicles was observed between the two videos, it was concluded that a passing maneuver had occurred on the passing zone. A total of 1,649 passes were observed on the calibration scenarios on the 53 hours of videos. Passing maneuvers from the twelve validation scenarios were 377 on 46 hours.

Finally, passing rates were calculated dividing the number of passing maneuvers by the following vehicles at each 15 -minute period. Consequently, a passing rate of 0.5 passes/following veh means that $50 \%$ of the vehicles following a leader inside a platoon performed a passing maneuver. 


\section{ANALYSIS OF THE RESULTS}

One of the common mistakes on the statistical analysis of the results is to model the phenomenon without checking the assumptions of the statistical tests. For example, linear regression cannot be applied to count data, such as number of following vehicles, because they are not normally distributed. On the analysis, the most appropriated statistical test for each variable was considered. The following variables were analyzed: following vehicles (FV); percentage of following vehicles $(\% \mathrm{FV})$; passing frequency $(\mathrm{PF})$; and, passing rates $(\mathrm{PR})$. The results are presented on the following sections.

\section{Traffic characteristics}

Following vehicles and percentage of following vehicles were analyzed to characterize the traffic flow on the beginning of the passing zones.

As following vehicles are nonnegative integer values, usual statistical tests based on the assumption of a normal distribution, such as linear regression, cannot be applied. Usually, count data are modeled with a Poisson regression model. The Poisson model assumptions of non-truncated data, equality of mean and variance and non-preponderance of zeros were met. Consequently, the Poisson regression model was applied. The results of the Poisson regression model indicated that the one-way volume (veh/h) explained an $87 \%$ of the following vehicles variance $\left(\alpha=5 \%, R_{p}\right.$-Squared $\left.=86.8 \%\right)$, as Equation 1 shows. As observed, the number of following vehicles increases as the one-way traffic volume increases. The statistics are summarized on Table 3.

$$
\mathrm{FV}=\exp \left(1.35206+0.0277104 * V_{p}\right)
$$

Where: FV is the number of following vehicles in a 15 -minute period (veh/h) and $\mathrm{Vp}$ is the one-way traffic volume for a 15 -minute period $(\mathrm{veh} / \mathrm{h})$.

\section{TABLE 3 Poisson regression analysis for following vehicles}

\begin{tabular}{|c|c|c|c|c|c|c|c|}
\hline \multicolumn{4}{|c|}{ Poisson Regression Analysis } & \multicolumn{4}{|c|}{ Deviance Analysis } \\
\hline Parameter & Estimate & Standard error & $\begin{array}{l}\text { Estimated } \\
\text { rate ratio }\end{array}$ & Source & Deviance & DF & P-Value \\
\hline CONSTANT & 1.35206 & 0.0278301 & & Model & 4624,99 & 1 & 0.0000 \\
\hline $\begin{array}{c}\text { One way traffic } \\
\text { volume }\end{array}$ & 0.027710 & 0.0003904 & 1.0281 & Residue & 697,759 & 454 & 0.0000 \\
\hline & & & & $\begin{array}{l}\text { Total } \\
\text { (Corr.) }\end{array}$ & 5322.75 & & 55 \\
\hline
\end{tabular}

On the other hand, the percentage of following vehicle was a continuous data set. Probability plot, skewness and kurtosis were carried out to verify if data were distributed as a normal distribution. The results indicated that the variable was normally distributed. As the other assumptions of linear regression analysis were fulfilled, a linear regression model (Table 4) was elaborated for the percentage of following vehicles $(\alpha=5 \%$, R-Squared $=64.6 \%)$. It could be observed that the percentage of following vehicles increased as the one-way traffic volume increases (Equation 2). 
5 TABLE 4 Multiple regression analysis for percentage of following vehicles

\begin{tabular}{|c|c|c|c|c|c|c|c|c|c|c|}
\hline \multicolumn{7}{|c|}{ Multiple Regression Analysis } & \multicolumn{6}{c|}{ Variance Analysis } \\
\hline Parameter & Estimate & $\begin{array}{c}\text { Standard } \\
\text { error }\end{array}$ & $\begin{array}{c}\text { t- } \\
\text { statistic }\end{array}$ & $\begin{array}{c}\text { P- } \\
\text { value }\end{array}$ & Source & $\begin{array}{c}\text { Squares } \\
\text { Sum }\end{array}$ & DF & $\begin{array}{c}\text { mean } \\
\text { square }\end{array}$ & $\begin{array}{c}\text { F- } \\
\text { Ratio }\end{array}$ & $\begin{array}{c}\text { P- } \\
\text { Value }\end{array}$ \\
\hline CONSTANT & 0.119165 & 0.00825645 & 14.433 & 0.0000 & Model & 5.27343 & 1 & 5.27343 & 831.83 & 0.0000 \\
\hline $\begin{array}{c}\text { One way } \\
\text { traffic } \\
\text { volume }\end{array}$ & 0.004613 & 0.00015994 & 28.8414 & 0.0000 & Residue & 2.87816 & 454 & 0.00633 & \\
\hline \multicolumn{70}{|c|}{$\mathrm{DF}=$ degrees of freedom; corr. $=$ correlation; } \\
\end{tabular}

7 Passing frequency

8 Passing frequency was studied using the absolute number of passes in a 15-minute period in order to 9 compare with other studies. In order to analyze whether the passing frequency among passing zones and traffic volume was equal, parametric and nonparametric tests could be developed. Parametric tests are vastly used and preferred because they are more powerful and are more likely to lead correctly to rejection of a false null hypothesis. However, the variables should be approximate normal. As passing frequencies in a 15-minute period failed to be distributed as a normal distribution, the nonparametric techniques should be considered.

The Kruskal-Wallis test is the nonparametric equivalent to the independent samples singlefactor analysis of variance. The test is sensitive to the differences in location (mean or median) between the populations and it is identical to the Mann-Whitney U test for comparing more than two populations. The null hypothesis is that all populations have the same locations (median or mean). Passing frequencies were tested to have the same location considering the passing zone length. The results of the Kruskal-Wallis test (sample passing zone $=114$; D-statistic $=105.681 ; \mathrm{p}$-value D-statistic $=0.0000$ ) indicated statistical differences among values of passing frequencies at a $95 \%$ level of confidence. The same test was performed based on the traffic volume on the four passing zones. The results of the Kruskal-Wallis test (sample traffic volume intervals $=[10,166]$; D-statistic $=130.386$; $p$-value D- $_{\text {- }}$ statistic $=0.0000$ ) also indicated that the different traffic volume produced statistically significant differences on the passing frequency.

As the passing frequency had statistically significant differences depending on the passing zone length and the two-way traffic volume, a regression analysis was carried out. Given that the passes are nonnegative integer values, the variable was modeled as a Poisson regression model. The assumptions of the model (non-truncated data, same mean and variance, and non-preponderance of zeros) were fulfilled. The best fit of Poisson regression model (Table 5) is shown in Equation 3 ( $\alpha=$ $5 \%, \mathrm{R}_{\mathrm{p}}$-Squared $=62.1 \%$ ).

$$
\mathrm{PF}=\exp \left(-4.57904-0.00125^{*} V_{p}^{2}-0.0000013^{*} L^{2}+2.75645^{*} \mathrm{P}+0.04093^{*} V_{p}+0.003455 * L\right)
$$

Where: \% FV is the percentage of following vehicles in a 15-minute period (veh/veh) and $\mathrm{Vp}$ is the one-way traffic volume for a 15 -minute period $(\mathrm{veh} / \mathrm{h})$. 
Where: PF is the passing frequency on the travel direction in a 15 -minute period (passes/h); $2 \mathrm{Vp}$ is the two-way traffic volume for a 15 -minute period $(\mathrm{veh} / \mathrm{h}) ; \mathrm{L}$ is the length of the passing zone 3 (m); and $\mathrm{P}$ is the traffic proportion on the travel direction.

5 TABLE 5 Poisson regression analysis for passing frequency

\begin{tabular}{|c|c|c|c|c|c|c|c|}
\hline \multicolumn{4}{|c|}{ Poisson Regression Analysis } & \multicolumn{4}{|c|}{ Deviance Analysis } \\
\hline Parameter & Estimate & $\begin{array}{c}\text { Standard } \\
\text { error }\end{array}$ & $\begin{array}{c}\text { Estimated } \\
\text { rate ratio }\end{array}$ & Source & Deviance & DF & P-Value \\
\hline CONSTANT & -4.57904 & 0.327803 & & Model & 1052.11 & 5 & 0.0000 \\
\hline $\begin{array}{l}\text { Two-way traffic } \\
\text { volume } 2\end{array}$ & -0.000125 & 0.000011536 & 0.999874 & Residue & 641.783 & 450 & 0.0000 \\
\hline Length^2 & -0.0000013 & $3.01931 \mathrm{E}-7$ & 0.999999 & $\begin{array}{l}\text { Total } \\
\text { (Corr.) }\end{array}$ & 1693.89 & 455 & \\
\hline Traffic proportion & 2.75645 & 0.37668 & 15.7438 & & & & \\
\hline $\begin{array}{l}\text { Two-way traffic } \\
\text { volume }\end{array}$ & 0.04093 & 0.00284811 & 1.04178 & & & & \\
\hline Length & 0.003455 & 0.000491578 & 1.00346 & & & & \\
\hline \multicolumn{8}{|c|}{$\begin{array}{c}\mathrm{DF}=\text { degrees of freedom; corr. }=\text { correlation; } \\
\mathrm{R}^{2}=62.1 \% ; \mathrm{R}^{2} \text { (adjusted) }=61.4 \%\end{array}$} \\
\hline
\end{tabular}

6

Figures 2 and 3 were generated applying Equation 3 varying: traffic volume and passing zone length. Traffic proportion was assumed 50/50 $(\mathrm{P}=0.5)$. Two-way traffic volume in vehicles per hour was represented to facilitate the analysis and it was calculated multiplying by 4 the traffic volume for a 15-minute period. Moreover, passing frequencies from other 12 passing zones were plotted in two series considering their length (lower than $750 \mathrm{~m}$ and higher than $750 \mathrm{~m}$ ). As traffic flow influenced the passing maneuver, three traffic flow levels were separated for each passing zone. The levels had similar sample and number of passing maneuvers. Therefore, the behavior was more homogeneous within the same level. Average traffic flow and average number of passes were calculated and plotted.

As seen in Figure 2, the longer the passing zone, the higher passing frequency in a 15-minute period. This influence depends on the traffic volume, as dispersion varies. On the other hand, there is an optimum traffic volume that maximizes the number of passes. The optimum two-way traffic volume is between 600 and $700 \mathrm{vh} / \mathrm{h}$ for all the passing zones. From that value, the number of passes decreases as the gaps on the opposing stream are shorter. 


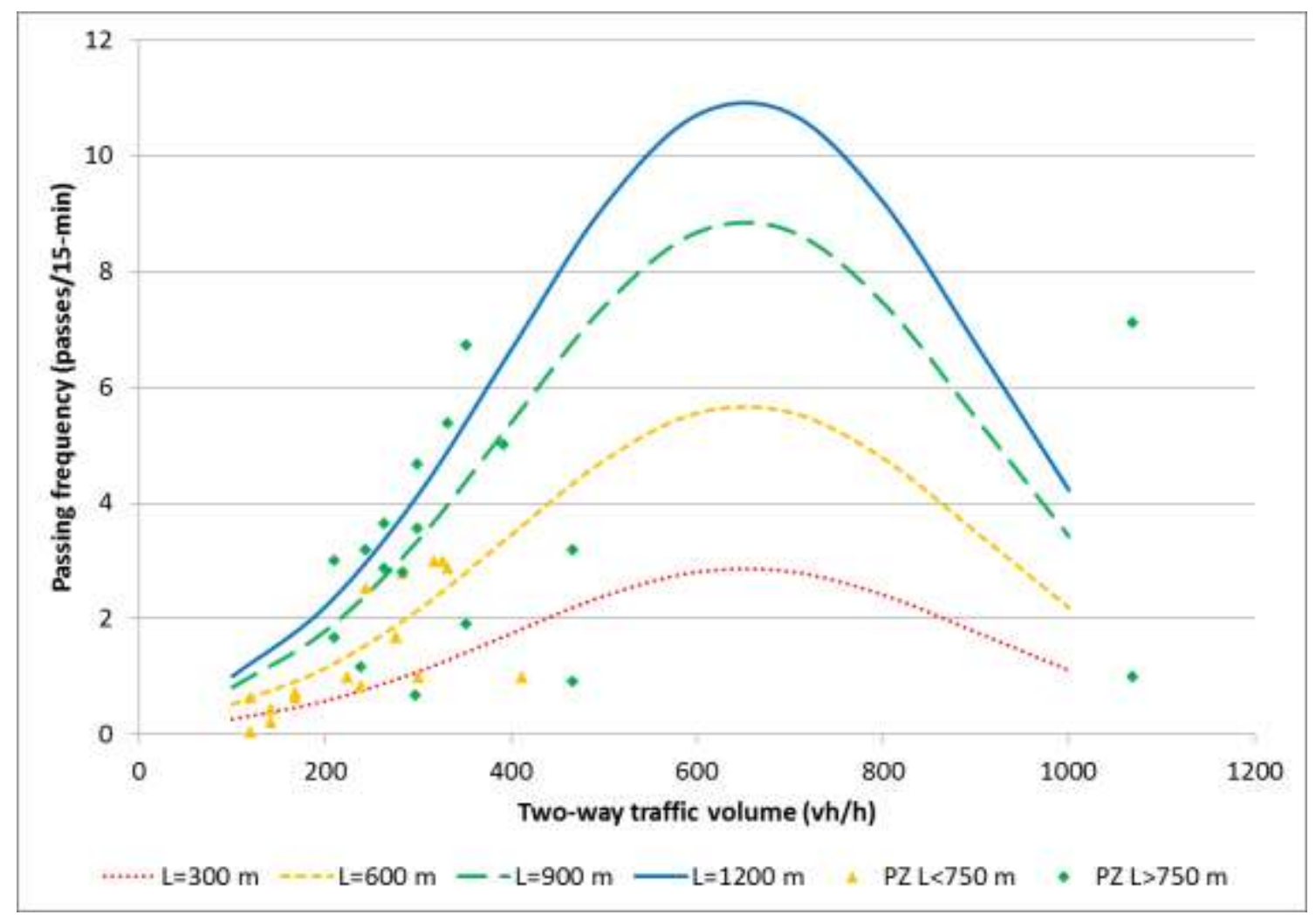

FIGURE 2 Traffic volume influence on passing frequency for balanced flows.

The model was validated with data from other twelve passing zones that were not introduced on the model. A good adjustment of the data to the model was found. However, passing frequencies of the CV-25 passing zones were different than the predicted because the traffic proportion in those highways was highly directional (between 90/10 and 70/30) and much higher than on the four passing zones of the model. Equation 3 was applied with CV-25 traffic proportion and the prediction was much more accurate.

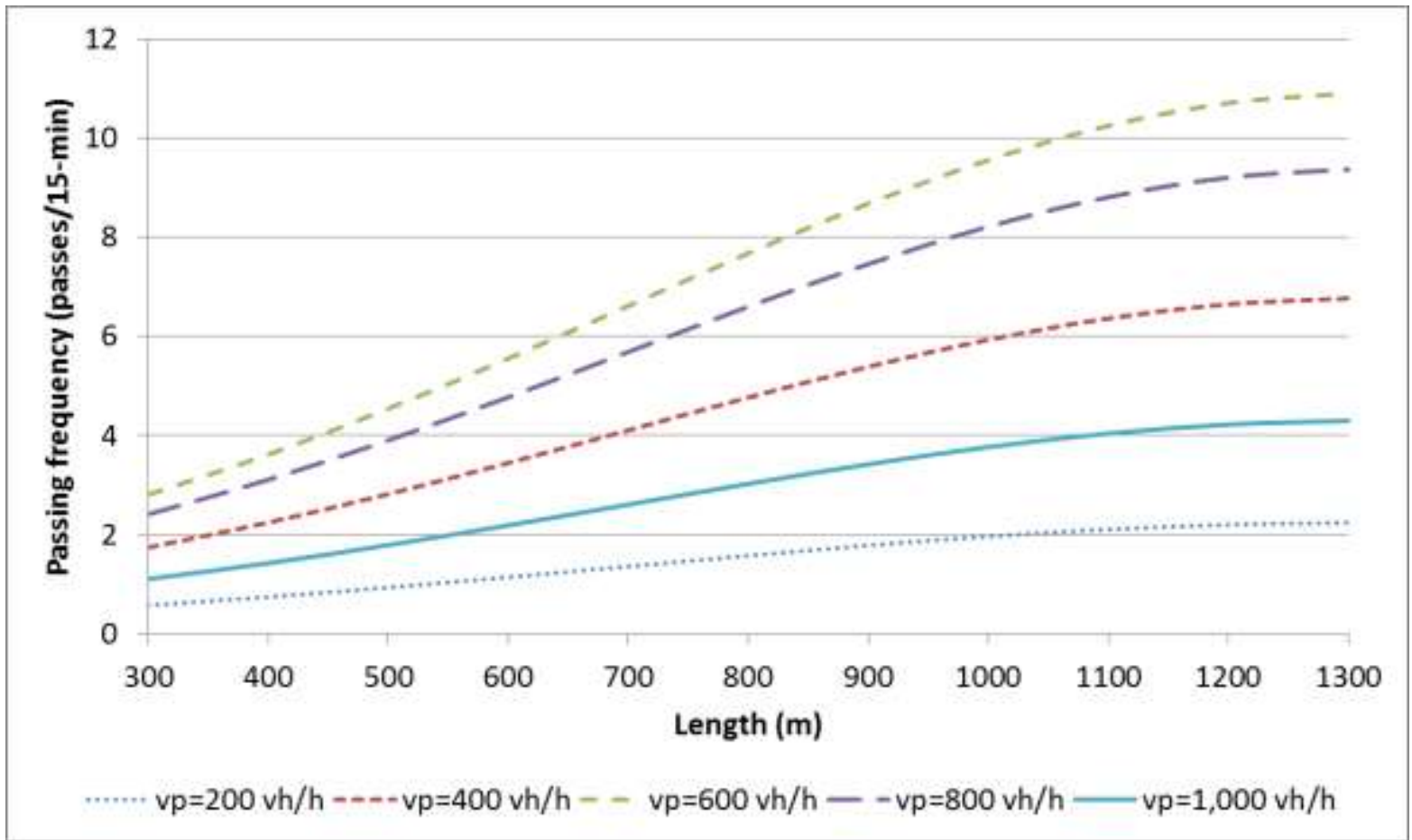

FIGURE 3 Passing zone length influence on passing frequency for balanced flows. 
The effect of passing zone length on passing frequency is represented on Figure 3: the longer passing zone, the higher passing frequency. The increase rate of passing frequency is almost linear until $1,100 \mathrm{~m}$. The increase rate also depended on traffic volume: the most favorable traffic volume was $600 \mathrm{veh} / \mathrm{h}$, because increasing $200 \mathrm{~m}$ the passing zone would increase 1.9 passes $/ 15 \mathrm{~min}$ the passing frequency. The same increasing of $200 \mathrm{~m}$ would generate an increase of $0.8,1.2,1.6$ and 0.4 passes/15 min with traffic volumes of 200, 400, 800 and 1,000 veh/h, respectively. From 1,100 m long, the increase rate is stabilized. Consequently, not the double of passing zone length may result in the double of passes, given traffic volume and traffic proportion. This could be explained because all drivers willing to pass would have already performed the maneuver. Thereafter, the length of the passing zones along the highway may be considered instead of the proportion of highway without passing zones because the increase on passing frequency due to passing zone length has lower effectiveness from passing zones longer than $1,100 \mathrm{~m}$.

\section{Passing rate}

Effectiveness of passing zones was studied depending on the absolute number of passes. However, this variable could not fully represent the phenomenon because not every vehicle in one passing zone is willing to pass. Consequently, passing rate was defined. The passing rate (PR) is the ratio between the number of passes in a 15-minute period and the percentage of following vehicles in that same period. This concept is equivalent to the overtaking ratio defined by Morrall and Werner (18).

Passing rates were tested to be distributed as a normal distribution. The normality plot, as well as the kurtosis and skewness indicated that passing rates were not normally distributed. Consequently, the variable was transformed to the square root of the passing rate $\left(\mathrm{PR}^{0.5}\right)$, which was normally distributed and usual statistic tests could be applied.

An ANOVA test was carried out to identify the influence variables on passing rate. The assumptions of the ANOVA test were fulfilled. The results indicated that the average values were statistically different among passing zones (F-statistic $=45.74 ; \mathrm{dg}=455 ; \mathrm{p}$-value F-statistic $=0.0000 ; \alpha=$ $5 \%)$.

As the assumptions of the multiple regression analysis were fulfilled, a forward-selection multiple regression analysis was performed to determine the variables that influenced on passing rates. The best fit regression model (Table 6) is presented in Equation $4\left(\alpha=5 \%, \mathrm{r}^{2}\right.$ adj $\left.=40.5 \%\right)$. The adjusted R-Square was lower than the passing frequency model. It could be possible that not all vehicles inside a platoon are willing to pass. Consequently, passing rates have more variability than passing frequencies.

$P R^{0.5}=0.638004+0.000228171^{*} \mathrm{~L}-0.297747^{*} \mathrm{P}-0.00174589^{*} v_{p}$

Where: PR is the passing rate on the travel direction in a 15-minute period (passes/following vehicle/15 min); $\mathrm{Vp}$ is the two-way traffic volume for a 15 -minute period (veh/15 $\mathrm{min}) ; \mathrm{L}$ is the length of the passing zone $(\mathrm{m})$; and $\mathrm{P}$ is the traffic proportion on the travel direction. 
2 TABLE 6 Multiple regression analysis for passing rate

\begin{tabular}{|c|c|c|c|c|c|c|c|c|c|c|}
\hline \multicolumn{9}{|c|}{ Multiple Regression Analysis } & \multicolumn{6}{c|}{ Variance Analysis } \\
\hline Parameter & Estimate & $\begin{array}{c}\text { Standard } \\
\text { error }\end{array}$ & $\begin{array}{c}\text { t- } \\
\text { statistic }\end{array}$ & $\begin{array}{c}\text { P- } \\
\text { value }\end{array}$ & Source & $\begin{array}{c}\text { Squares } \\
\text { Sum }\end{array}$ & DF & $\begin{array}{c}\text { mean } \\
\text { square }\end{array}$ & $\begin{array}{c}\text { F- } \\
\text { Ratio }\end{array}$ & $\begin{array}{c}\text { P- } \\
\text { Value }\end{array}$ \\
\hline CONSTANT & 0.638004 & 0.0653792 & 9.75852 & 0.0000 & Model & 5.94418 & 3 & 1.98139 & 86.26 & 0.0000 \\
\hline Length & 0.000228 & 0.00001956 & 11.6619 & 0.0000 & Residue & 8.54465 & 372 & 0.02296 & & \\
\hline $\begin{array}{c}\text { Two-way } \\
\text { traffic volume }\end{array}$ & -0.001745 & 0.00017091 & -10.2149 & 0.0000 & $\begin{array}{c}\text { Total } \\
\text { (Corr.) }\end{array}$ & 14.4888 & 375 & & & \\
\hline $\begin{array}{c}\text { Traffic } \\
\text { proportion }\end{array}$ & -0.297747 & 0.113547 & -2.62224 & 0.0091 & & & & & & \\
\hline \multicolumn{7}{|c|}{ DF= degrees of freedom; corr. = correlation; } \\
$\mathrm{R}^{2}=41.0 \% ; \mathrm{R}^{2}$ (adjusted) $=40.5 \%$ standard error of estimate $=0.1515 ;$ Average absolute error $=0.1160$ \\
\hline
\end{tabular}

As seen, the longer the passing zone, the higher passing rate. On the other hand, favorable traffic proportion resulted in higher passing rates. However, traffic volume was not statistically significant. It could be explained as the number of following vehicles is correlated with the traffic volume.

The influence of traffic volume and passing zone length on passing rate is shown in Figure 4. It was generated applying Equation 4 varying traffic volume and passing zone length. Similar to Figures 2 and 3, traffic proportion was assumed 50/50 (P=0.5) and two-way traffic volume in vehicles per hour was represented to facilitate the analysis. It was calculated multiplying by 4 the traffic volume for a 15 -minute period. Passing rates from the other 12 passing zones were also plotted with the same criteria.

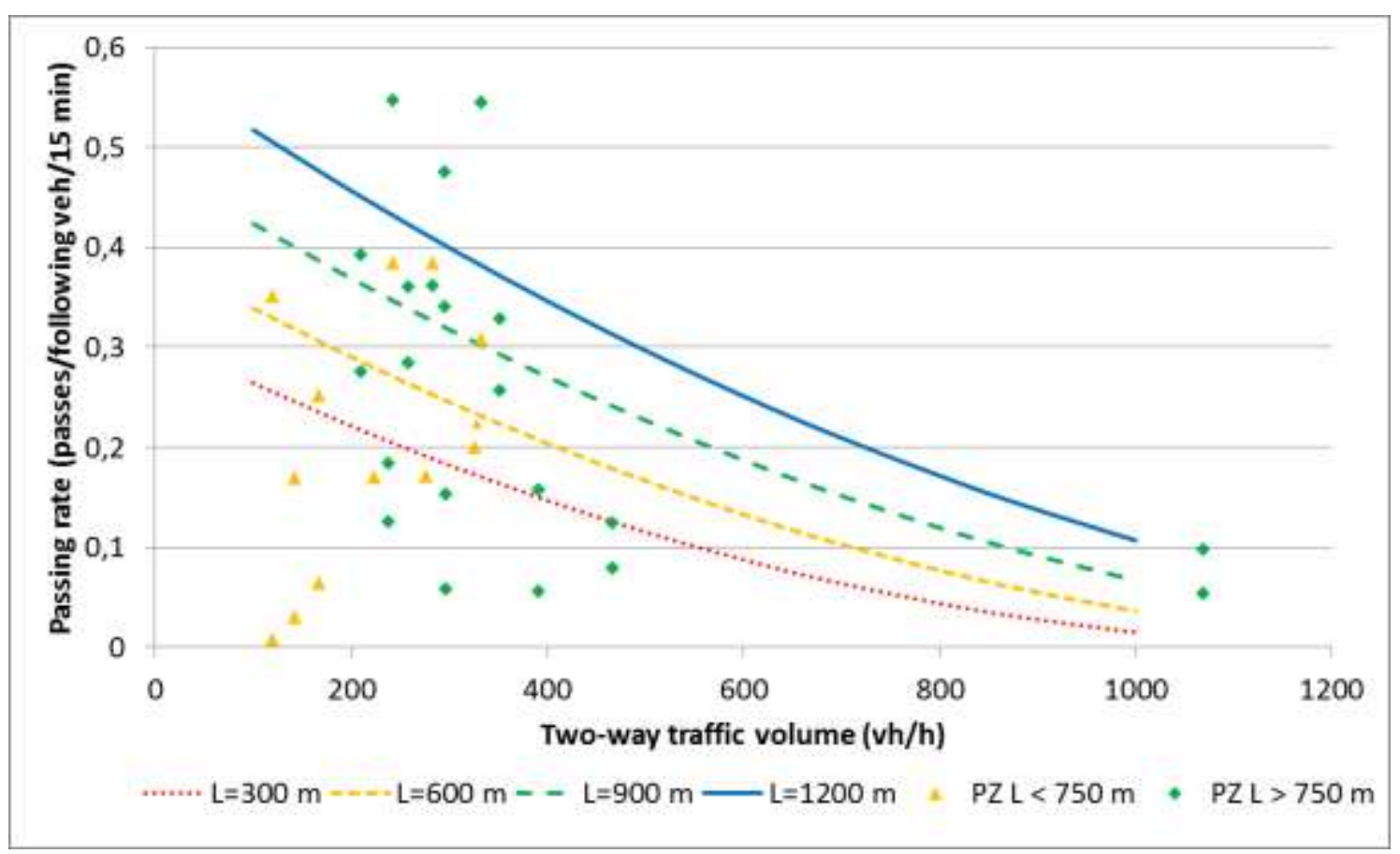

FIGURE 4 Traffic volume influence on passing rate for balanced flows.

The number of completed passes per following vehicle increases as the traffic volume decreases and the passing zone length increases. With short passing zones, only $26 \%$ of following 
vehicles can perform the maneuver even though traffic volume is quite low (200 veh/h) and passing gaps are available. For the same traffic volume, passing zones of 1,200 $\mathrm{m}$ increase the percentage of following vehicles that pass to $52 \%$. The results are consistent for all traffic volumes. However, the decrease rate is higher on longer passing zones as increasing $200 \mathrm{veh} / \mathrm{h}$ the two-way traffic flow would reduce the percentage of following drivers that pass in $10 \%, 8 \%, 8 \%$ and $6 \%$ for passing zones length of 1,200, 900, 600 and $300 \mathrm{~m}$, respectively. On the other hand, an optimum traffic volume that maximizes passing rate was not found because even though the number of passes was higher with traffic volumes between 600 and $700 \mathrm{veh} / \mathrm{h}$, the following vehicles were also higher. Consequently, the percentage of following vehicles that passed always decreases with traffic volume.

Figure 4 could be used twofold. The first option is to calculate the passing zone length needed to provide a certain passing rate given the traffic volume of the highway. The second option is to evaluate until which traffic volume of the highway a certain passing rate could be guaranteed given the passing zone length. So, the model could be used to determine the minimum passing zone length or maximum traffic volume that provides a determinate passing rate.

Adjustment of validation data to the model was lower on passing rates than on passing frequency due to their higher dispersion. However, it can be observed that longer passing zones presented higher passing rates. Consequently, passing rate variability may be too high to consider this variable even though the better representation of the phenomenon.

\section{DISCUSSION}

The Highway Capacity Manual (3) includes passing zones effect on two-lane highways traffic operation on both ATS (average travel speed) and PTSF (percentage time spent following). ATS is affected by the adjustment for percentage of no-passing zones: ATS is reduced is the percentage of no-passing zones increases. Given a highway segment length, more passing zone length along the highway would lead to higher ATS. Consequently, it assumes that the improvement on traffic operation of passing zones is equal regardless their length: one passing zone of 1,500 $\mathrm{m}$ would have the same effects on traffic operation than two passing zones of $750 \mathrm{~m}$. However, the developed model indicated that even though passing frequency increases as the length of the passing zone increases, the increase rate is much lower from 1,100 m passing zone length. Consequently, two passing zones of $750 \mathrm{~m}$ would produce more passes and ATS would be higher than on a single passing zone of 1,500 $\mathrm{m}$. Thereafter, the percentage of no-passing zones would not reliably represent effectiveness of passing zones. Effectiveness of every single passing zone should be considered instead.

Furthermore, the adjustment also depends on the flow rate for peak 15-min period. Given a percentage of no-passing zones, reduction in ATS is maximum for two-way demand flow (vp) of 400 $\mathrm{veh} / \mathrm{h}$, and its influence is stabilized for vp higher than $1,800 \mathrm{veh} / \mathrm{h}$ or more. The proposed model indicates that passing frequency is optimized for traffic volumes between 600 and $700 \mathrm{veh} / \mathrm{h}$. Consequently, reduction in ATS should be minimized on that range. Moreover, if traffic volume was higher than $800 \mathrm{veh} / \mathrm{h}$ passing frequency was highly reduced. So, the adjustment factor should be reduced for traffic flows of 600 and $800 \mathrm{veh} / \mathrm{h}$ and then increased for higher traffic flows.

On the other hand, PTSF is adjusted by the combined effect of the directional distribution of traffic and of the percentage of no-passing zones. The adjustment depends on percentage of nopassing zones, two-way flow rate and traffic proportion. An increase on no-passing zone percentage would result in higher PTSF and worse level of service. Similarly to the previous discussion, effectiveness of every passing zone should be considered instead the percentage of no-passing zones. Besides, increase in PTSF is maximum for two-way flow rate of $400 \mathrm{veh} / \mathrm{h}$ on balanced flows. Nevertheless, the obtained model does not represent the same behavior. Thereafter, the adjustment 
factor should be reduced for traffic flows of 600 and $800 \mathrm{veh} / \mathrm{h}$ and then increased for higher traffic flows. Traffic proportion should also be considered. However, its effect is lower than other variables.

Conversely, the passing rate model was compared with the overtaking ratios proposed by Morrall and Werner (18). Both parameters decreased with two-way traffic volume. However, their maximum expected passing rate was $85 \%$, compared to the $52 \%$ of the proposed model. The main reason for this difference is the passing behavior. Morrall and Werner used a traffic simulation model where drivers will to pass if their desired speed was lower than the impeding vehicle. However, some drivers adapt their speed to the previous vehicle and accept that delay on their trip: these drivers would not perform a passing maneuver. Consequently, the number of passes with low traffic volume decreases, and the maximum passing rate is lower. Besides, the effect of two-way traffic volume was higher on their simulations than on the model, as the expected passing rate decreased from 85 to $10 \%$ at a traffic volume of $800 \mathrm{veh} / \mathrm{h}$. Furthermore, the minimum passing rate was stabilized at $2 \%$. The higher decrease rate is also explained because of the passing behavior on the traffic simulation model. However, Morrall and Werner presented the percentage of no-passing zones instead of single passing zones. So, their values cannot be directly compared with the model.

Finally, the results were compared with Romana's study (1). Overall passing rates were presented for a whole highway segment including no-passing zones instead of single passing zones. Consequently, no comparison was possible without further data. However, his data showed a maximum passing frequency for a balanced two-way traffic flow between 500 and $800 \mathrm{veh} / \mathrm{h}$. This optimum value is similar to the one given on the model, which is located between 600 and $700 \mathrm{veh} / \mathrm{h}$.

\section{CONCLUSIONS}

Passing maneuvers have been deeply studied in highway engineering to determine criteria to establish no-passing zones, as many of the studies are focused on the maneuver itself and how is performed on different conditions. However, the interaction between vehicles traveling in the same and in opposing lanes affects traffic operations. Most of the studies are focused on percentage of following vehicles or the adjustment of the HCM procedure to local data. However, these variables are influenced by the effectiveness of passing zones and how they could reduce the number of following vehicles. In fact, only a few studies on the expected number of passes on a highway considering the percentage of nopassing zones have been carried out.

This research presented an analysis of the effectiveness of passing zones considering their length and traffic volume. Four passing zones located on the same rural highway in Spain were selected. They presented two-way traffic volumes between 120 and $900 \mathrm{veh} / \mathrm{h}$; and lengths between 265 and $1,270 \mathrm{~m}$. More than 1,600 passing maneuvers were recorded during the 53 hours of observation on the scenarios.

Passing frequency and passing rate were selected as passing zone effectiveness measures. Passing frequency is defined as the number of passes per 15-minute observation period. The count data were modeled following a Poisson regression model. The results indicated that the longer the passing zone, the higher number of passes in the period. However, the improvement on passing frequency is more stable from passing zone lengths longer than $1,100 \mathrm{~m}$. From that length, the effectiveness of the passing zones decreases because the drivers willing to pass would perform the maneuver with shorter passing zones and the increase would only affect to very conservative drivers that need much longer gaps on the opposing stream. On the other hand, balanced flows with two-way traffic volumes between 600 and $700 \mathrm{veh} / \mathrm{h}$ optimized the number of passes. This result was consistent for all lengths and suggested that passing is more effective for that traffic conditions.

Even though passing frequency quantifies the number of passes in a passing zone, this measure is not enough to fully represent the phenomenon: passing maneuvers need a faster vehicle 
impeded by a lower vehicle; so, not every vehicle that enters a passing zone is willing to pass. Consequently, passing rate was defined as the number of passes per following vehicle per 15-minute observation period. Passing rate decreased as traffic volume increased, for all passing zones. So, the increase in the passing frequency with the traffic volume is lower than the increase of following vehicles. Besides, the model predicted that the maximum percentage of drivers that follow a vehicle and could perform a passing maneuver was $52 \%$; with two-way traffic volume of $200 \mathrm{veh} / \mathrm{h}$ and passing zone length of $1,200 \mathrm{~m}$. The model could be used to determine the minimum passing zone length or maximum traffic volume that provides a determinate passing rate.

The passing frequency and passing rate models were validated with data from other twelve additional passing zones. The additional scenarios presented different traffic volumes and lengths. 377 passes were observed on the validation scenarios during more than 46 hours. The passing frequency model was accurately adjusted to the additional data while the passing rates presented the same trends but with higher dispersion. Thereafter, even though this variable better represents the phenomenon, its variability may be too high for consideration.

The results were compared with the 2010 Highway Capacity Manual analysis procedure for two-lane highways. Adjustments on average travel speed and percentage time spent following based on percentage of no-passing zones do not reliably represent effectiveness of passing zones. Effectiveness of every passing zone should be considered instead.

Finally, the paper presented a new approach to two-lane highway traffic performance based on the effectiveness of passing zones. General conclusions on passing zones effectiveness were given. Further research will be carried out to reduce more data such as vehicles' speeds. The results could be used to calibrate a traffic simulation model on two-lane highways in order to generate new highway scenarios and propose reliable thresholds on traffic operation quality.

\section{ACKNOWLEDGEMENTS}

Authors would like to thank Spanish Ministry of Science and Innovation that subsidizes the research project with reference code TRA2010-21736, and Spanish Ministry of Public Works, for its collaboration during the field study.

\section{REFERENCES}

1. Romana, M. G. Passing Activity on Two-Lane Highways in Spain, Transportation Research Record: Journal of the Transportation Research Board, No. 1678, 1999, pp.90-95.

2. Molinero, A., E.Carter, C. Naing, M.C. Simon and T. Hermitte. Part 1. Overview and general statistics, Accident causation and pre-accidental driving situations (TRACE - Traffic Accident Causation in Europe Internal Report), 2008.

3. Transportation Research Board. Highway Capacity Manual, 2010.

4. Al-Kaisy, A. and Z. Freedman. Estimating Performance on Two-Lane Highways: Case Study Validation of a New Methodology, Transportation Research Record, No. 2173, 2010, pp.7279.

5. Al-Kaisy, A. and S. Karjala. Car-following interaction and the definition of free-moving vehicles on two-lane rural highways, Journal of Transportation Engineering, Vol. 136, No. 10, 2010, pp.925-931.

6. Al-Kaisy, A. and C. Durbin. Platooning on two-lane two-way highways: an empirical investigation, Procedia and Behavioral Sciences, No. 16, 2011, pp. 329-339.

7. Gattis, J.L., M.S. Alguirre, K. Townsend and S. Rao. Rural two-lane passing headways and platooning. Transportation Research Record: Journal of the Transportation Research Board, No. 1579, 1997, pp. 27-34. 
8. Dixon, M.P., S.S. Sarepali and K.A. Young. Field evaluation of highway capacity manual 2000 analysis procedures for two-lane highways. Transportation Research Record: Journal of the Transportation Research Board, No. 1802, 2002, pp. 125-132.

9. Polus, A. and M. Cohen. Theoretical and empirical relationships for the quality of flow and for a new level of service on two-lane highways. Journal of Transportation Engineering, Vol 135, No. 6, 2009, pp. 380-385.

10. Rozenshtein, S., A. Polus and M. Cohen. Models for estimating drivers following on two-lane rural highways, presented at Transportation Research Board 91st Annual Meeting, 2012, Washington D.C.

11. Al-Kaisy, A. and C. Durbin. Evaluating new methodologies for estimating performance on two-lane highways. Canadian Journal of Civil Engineering, Vol. 35, 2008, pp.777-785.

12. Luttinen, T. Level of service on Finnish two-lane highways. Transportation Research Circular E-C018: $4^{\text {th }}$ International Symposium on Highway Capacity, 2000, Hawaii.

13. Romana, M. and M. López. Estimación del porcentaje de vehículos demorados en función de las variables de la circulación en carreteras convencionales de doble sentido. Revista de Obras Públicas, Vol. 3359, 1996, pp.85-93.

14. Romana, M. Evaluación práctica de niveles de servicio de carreteras convencionales de dos carriles en España. Centro de Estudios y Experimentación de Obras Públicas, 1997, Madrid.

15. Transportation Research Board. Highway Capacity Manual, 1985.

16. Messer, C.J. Two lane, two way rural highway capacity. Final report. National Cooperative Highway Research Board. 1983.

17. Luttinen, T. Uncertainty in the Operational Analysis of Two-lane Highways. TL Consulting Engineers, 2001.

18. Morrall, J. and A. Werner. Measuring level of service of two-lane highways by overtakings. Transportation Research Record: Journal of the Transportation Research Board, No. 1287, 1990, pp. 62-69.

19. Llorca, C and A. García. Evaluation of Passing Process on Two-lane Rural Roads in Spain using a New Methodology Based on Video Data, Transportation Research Record: Journal of the Transportation Research Board, No. 2262, 2011, pp. 42-51. 